\title{
Changes of the Nucleolus Architecture in Absence of the Nuclear Factor CTCF
}

\author{
A. Hernández-Hernández ${ }^{a, b} \quad$ E. Soto-Reyes ${ }^{a} \quad$ R. Ortiz ${ }^{b} \quad$ C. Arriaga-Canon ${ }^{a}$ \\ O.M. Echeverría-Martinez ${ }^{b} \quad$ G.H. Vázquez-Nin ${ }^{b} \quad$ F. Recillas-Targa ${ }^{a}$

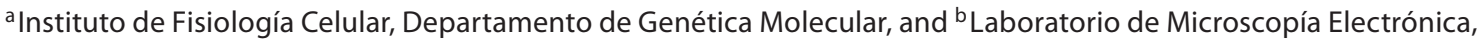 \\ Facultad de Ciencias, Universidad Nacional Autónoma de México, Mexico City, México
}

\section{Key Words}

Dense fibrillar components $\cdot$ CTCF $\cdot$ Nucleolus $\cdot$ Nucleolus

organizer region $\cdot$ Silver staining

\begin{abstract}
CTCF is a multifunctional nuclear factor involved in many cellular processes like gene regulation, chromatin insulation and genomic organization. Recently, CTCF has been shown to be involved in the transcriptional regulation of ribosomal genes and nucleolar organization in Drosophila cells and different murine cell types, including embryonic stem cells. Moreover, it has been suggested that CTCF could be associated to the nucleolus of human erythroleukemic K562 cells. In the present work, we took advantage of efficient small hairpin RNA interference against human CTCF to analyze nucleolar organization in HeLa cells. We have found that key components of the nucleolar architecture are altered. As a consequence of such alterations, an upregulation of ribosomal gene transcription was observed. We propose that CTCF contributes to the structural organization of the nucleolus and, through epigenetic mechanisms, to the regulation of the ribosomal gene expression.
\end{abstract}

Copyright $\odot 2012$ S. Karger AG, Basel

A.H.-H. and E.S.-R. contributed equally to the present work.
Genomic organization in the eukaryotic cell nucleus plays an important role in gene expression regulation. There are several players involved in this phenomenon, one of them is the CCCTC-binding factor also known as CTCF [Guelen et al., 2008; Phillips and Corces, 2009]. The function of CTCF is mediated by different posttranslational modifications like SUMOylation, phosphorylation and poly(ADP-ribosyl)ation [Caiafa and Zlatanova, 2009; Farrar et al., 2010]. Furthermore, CTCF has been shown to be involved in several processes, like the protection against de novo DNA methylation, regulation of genomic imprinting and chromatin organization, among others [De La Rosa-Velázquez et al., 2007; Guelen et al., 2008; Cuddapah et al., 2009; Soto-Reyes and Recillas-Targa, 2010; Recillas-Targa et al., 2011]. This multifunctionality can be attributed to the ability of CTCF to bind a wide variety of DNA sequences and proteins using different combinations of its 11 zinc fingers. Until now, around 16,000 CTCFbinding-sites have been annotated in the human genome [Barski et al., 2007; Kim et al., 2007; Martin et al., 2011]. Notably, around one third of these binding sites correlate with intergenic regions, further supporting its structural role [Zlatanova and Caiafa, 2009]. In the majority of cells, CTCF is localized in the whole nuclear volume, but during the cell cycle it has been associated with mitotic chromosomes, and in some cases in the nucleolus, suggesting its activity in ribosome biogenesis [Zhang et al., 2004].

\section{KARGER \\ Fax +41613061234 E-Mail karger@karger.ch} www.karger.com
(C) 2012 S. Karger AG, Base

$1424-8581 / 12 / 1362-0089 \$ 38.00 / 0$

Accessible online at:

www.karger.com/cgr
Félix Recillas-Targa

Instituto de Fisiología Celular, Departamento de Genética Molecular

Universidad Nacional Autónoma de México, Apartado Postal 70-242

Mexico City 04510 (Mexico)

Tel. +52 55562256 74, E-Mail frecilla@ifc.unam.mx 
Some studies have demonstrated that CTCF copurifies with nucleolar proteins like nucleophosmin [Yusufzai et al., 2004]. In interphase cells, CTCF is located in the nucleus and excluded from the nucleolus. During mitosis, CTCF accumulates at centromeres, particularly during metaphase and anaphase. In telophase, CTCF dissociates from the centromeres and is relocated principally to the nucleus [Zhang et al., 2004].

It has been shown that CTCF can be translocated into the nucleolus during the differentiation of erythroleukemic cell line K562, during apoptosis of the MCF7 breast cancer line and in terminally differentiated mammalian cells [Torrano et al., 2006]. Furthermore, the nucleolar location of CTCF has been associated with cell cycle arrest in response to poly(ADP-ribosyl)ation [Torrano et al., 2006]. Such observations have been further confirmed in Drosophila and mammalian cells including embryonic stem cells [van de Nobelen et al., 2010; Guerrero and Maggert, 2011].

The nucleolus is the most prominent structure inside the nucleus, and principally functions in ribosomal biogenesis [Hernandez-Verdun, 2006]. There is evidence showing that the nucleolus is self-organized around multiple copies of ribosomal DNA (rDNA) comprising $43 \mathrm{~kb}$ in humans and $45 \mathrm{~kb}$ in mice, of which around $14 \mathrm{~kb}$ correspond to the ribosomal gene coding sequences and 30 $\mathrm{kb}$ to the intergenic domains. The ribosomal genes are transcribed by RNA polymerase I generating the $28 \mathrm{~S}, 18 \mathrm{~S}$ and $5.8 \mathrm{~S}$ ribosomal RNAs. The subset of actively transcribed ribosomal genes are embedded in a permissive chromatin configuration in which UBF nuclear factor (upstream binding factor) binding to the active transcription units seems to be a crucial event in switching the genes to an active state [McStay and Grummt, 2008; Sanij and Hannan, 2009]. The nucleolus has 3 principal components recognizable at the level of electron microscopy. The fibrillar components (FCs) are the regions where the rDNA is located. The FCs are partially or completely surrounded by an electron dense region known as dense fibrillar components (DFCs). These 2 components are considered as functional units where rDNA transcription takes place. The FCs and DFCs are surrounded by the granular component (GC), where the ribosomes are assembled [Cisterna and Biggiogera, 2010]. Torrano et al. [2006] showed that CTCF is present in the DFC region of the nucleolus of rat neurons, therefore suggesting a role of CTCF in either rDNA transcriptional control or in nucleolar architecture. More recently, it has been shown that CTCF directly interacts with the nucleolar protein UBF3 that is involved in nucleolus architecture and rDNA tran- scription [Sanij and Hannan, 2009; van de Nobelen et al., 2010].

The nucleolus is a good example that illustrates the way in which chromatin directly influences genome organization and function, in particular, through the formation and maintenance of heterochromatin to inactivate subsets of rDNA repeats. The epigenetic silencing of rDNA is mediated by the recruitment of the chromatin remodeling complex NoRC [Bierhoff et al., 2010]. Importantly, to be recruited to the rDNA gene promoters, the NoRC complex requires non-coding RNAs transcribed from the spacer promoters, which in turn contribute to the loading of DNA methyl-transferase Dnmt3b, which reinforces the epigenetic silencing of the rDNA repeats [Mayer et al., 2006, 2008; McKeown and Shaw, 2009; Bierhoff et al., 2010; Schmitz et al., 2010]. Therefore, equilibrium between heterochromatin formation, active transcription and an ordered 3-dimensional organization of the nucleoli is critical for cell survival. Based on such properties and knowing the variety of functions associated to CTCF it is attractive to propose its contribution to the nucleolus structure and function.

Here we show that CTCF depletion by means of small hairpin RNA interference (shRNAi) leads to nucleolar disorganization in HeLa cells mainly attributed to defects of the DFCs. Surprisingly, this effect is accompanied by an overexpression of ribosomal genes. These results support a dual model for CTCF activity in the nucleolus, through its participation in the structural organization of the nucleolus and epigenetic regulation of ribosomal gene expression.

\section{Material and Methods}

Stable Transfection of Small Hairpin RNA against CTCF in HeLa Cells

HeLa cell lines were grown in DMEM medium containing $10 \%$ fetal bovine serum (FBS) and $1 \%$ penicillin/streptomycin (Life Technologies, Gaithersburg, Md., USA). A small hairpin RNA (shRNA) targeting CTCF (pCT1, kindly provided by Ko Ishihara [Ishihara et al., 2006]) was transfected in a stable condition in HeLa cells using lipofectamine (LipofectAMINE 2000). These cells were selected for 3 weeks in the presence of puromycin $(1 \mu \mathrm{g} / \mathrm{ml})$.

\section{Western Blotting}

Cells were harvested with lysis buffer containing $20 \mathrm{mM}$ HEPES pH 7.9, $400 \mathrm{mM} \mathrm{KCl,} \mathrm{20 \%} \mathrm{glycerol,} 2$ mM DTT, plus protease inhibitors. Proteins were quantified by the Bradford assay (BioRad). After separation by sodium dodecyl sulfate polyacrylamide gel electrophoresis, resolved proteins were transferred to a PVDF membrane (Pharmacia). Membranes were blocked with 5\% 
nonfat milk for $2 \mathrm{~h}$ and then incubated with the appropriate antibody overnight at $4^{\circ} \mathrm{C}$. After washing, the blots were incubated for $1 \mathrm{~h}$ with an appropriate horseradish peroxidase-conjugated secondary antibody (Santa Cruz Biotechnology), washed and the antibody-reactive proteins were detected with a chemiluminescence substrate according to the manufacturer's instructions (Pierce).

\section{Silver Staining of the Nucleolus Organizer Region}

HeLa cells were grown on coverslips for $48 \mathrm{~h}$ and fixed with $1 \%$ paraformaldehyde for $10 \mathrm{~min}$ at RT. Coverslips were incubated for $5 \mathrm{~min}$ in a freshly prepared solution of gelatin-formic acid of a ratio of 1:2 and 50\% silver nitrate in distilled water. They were rinsed in distilled water, dehydrated throughout graded ethanol solutions and immersed into a mix of 1:1 ethanol and xylol and then covered with pure xylol. Coverslips were mounted on slides with entellan as mounting medium and observed in an optical microscope (Nikon $600 \mathrm{E}$ ). Images were captured with a 12-megapixel digital camera and with the Imager software.

\section{Electron Microscopy}

HeLa cells were harvested after $24 \mathrm{~h}$ of incubation and pelleted in a $1.5-\mathrm{ml}$ tube. The pellets were washed twice with PBS and fixed with $2.5 \%$ glutaraldehyde plus $4 \%$ paraformaldehyde in PBS for 90 min at RT. The fixed cells were washed 3 times with PBS and then postfixed with $1 \%$ osmium tetroxide for $1 \mathrm{~h}$ in PBS. They were dehydrated through graded ethanol solutions, embedded in Epon and polymerized at $65^{\circ} \mathrm{C}$ for $2 \mathrm{~d}$. Semithin sections were mounted on glass slides and stained with toluidine blue before examination. Ultrathin sections were mounted on formvar-coated grids and stained with uranyl acetate and lead citrate before examination in a transmission electron microscope at $80 \mathrm{kV}$.

\section{Ultrastructural AgNOR and Gold Immunolabeling}

HeLa cells were harvested after $24 \mathrm{~h}$ of incubation and pelleted in a $1.5-\mathrm{ml}$ tube. The pellets were washed twice with PBS, fixed with $4 \%$ paraformaldehyde in PBS for 90 min at $4^{\circ} \mathrm{C}$ and dehydrated through graded methanol solutions at $4^{\circ} \mathrm{C}$. Samples were embedded in Lowicryl K4M and polymerized in a UV chamber for $24 \mathrm{~h}$ at $4^{\circ} \mathrm{C}$ and then for $24 \mathrm{~h}$ at RT. For silver staining of the nucleolus organizer region (AgNOR staining), ultrathin sections mounted on formvar-coated grids were incubated with a freshly prepared solution of gelatin-formic acid of a ratio of 1:2 and 50\% silver nitrate in distilled water for $5 \mathrm{~min}$, rinsed with distilled water and observed in a transmission electron microscope at $80 \mathrm{kV}$. For immunolabeling, ultrathin sections mounted on formvarcoated grids were incubated with 3\% BSA in PBS for $1 \mathrm{~h}$ at RT and then with anti-CTCF antibody 1:50 (Millipore cat. 07-729) in PBS, rinsed with PBS 3 times 20 min each and incubated with the secondary antibody coupled to $10 \mathrm{~nm}$ gold beads. Samples were contrasted with uranyl acetate before examination in a transmission electron microscope at $80 \mathrm{kV}$.

Quantitative Real-Time Polymerase Chain Reaction

Relative RNA levels were quantified by real-time polymerase chain reaction (qRT-PCR). Briefly, cDNA was synthesized using AMV reverse transcriptase and oligo dT (Promega). Samples were treated with $1 \mu \mathrm{g}$ of DNase I (RQ1, Promega). Quantitative RTPCR measurements (qPCR) were done by using SYBR green PCR mix (Qiagen). The PCR reaction was carried out in an ABI PRISM
7000 detection system (Perkin Elmer) at $50^{\circ} \mathrm{C}$ for 2 min and $95^{\circ} \mathrm{C}$ for $10 \mathrm{~min}$, followed by 40 two-step cycles of $95^{\circ} \mathrm{C}$ for $15 \mathrm{~s}$ and $60^{\circ} \mathrm{C}$ for $1 \mathrm{~min}$. Relative $\mathrm{mRNA}$ levels were calculated using the comparative $\Delta \Delta \mathrm{Ct}$ method.

\section{Results}

\section{Effect of CTCF Depletion on Nucleolar Organization}

To investigate the role of CTCF in nucleolus structure we used a shRNAi against the human CTCF nuclear factor in HeLa cells. We transfected HeLa cells in a stable form (HeLa-kd-CTCF) with the shRNAi against CTCF and, as control, we used a HeLa-empty-vector cell line (HeLa-empty-vector). We first monitored the diminishment of CTCF by Western blot (fig. 1A). Then, in order to evaluate the effect of the absence of CTCF on nucleolus structure, we performed the argentic impregnation assay or AgNOR staining, which is used to stain nucleolus organizer regions (NORs) and determinate defects in nucleolus structure [Trere et al., 2004] (fig. 1B). The shape of the nucleoli in HeLa-empty-vector cells was homogeneous in $88 \%$ of the observed cells (fig. 1B1) and the NOR staining was localized in the nucleolus (fig. 1B3). In contrast, in HeLa-kd-CTCF cells, nucleolus shapes were altered (fig. 1B2) and NORs were not visible by the AgNOR staining (fig. 1B4). We observed $81 \%$ of cells $(n=100)$ with altered nucleolus shape (disharmonic nucleolus) in HeLa-kd-CTCF, whereas only $12 \%$ of cells with disharmonic nucleolus structure were seen in HeLa-empty-vector cells (fig. 1C). These results suggest that the absence of CTCF causes a disorganization of the nucleolar components.

\section{Ultrastructural Analysis of HeLa Cells Lacking CTCF}

In order to evaluate the nucleolar defects attributed to the absence of CTCF with improved resolution we performed ultrastructural analyses of the nucleolar components. In HeLa-empty-vector cells, as well as in nontreated HeLa cells, we could identify the FCs and the GC of the nucleolus (fig. 2A and data not shown). In HeLa-kdCTCF cells, we observed different degrees of disorganization of the nucleolar components (fig. 2B-D). In these cells, the GC formed the bulk mass of the nucleolus as in HeLa-empty-vector cells; however, this component was observed from partially to completely segregated (fig. 2BD). More striking is the absence of well-defined FCs and DFCs in the GC (fig. $2 \mathrm{~B}-\mathrm{D}$ ), rather we observed holes where the FCs were supposed to be located (fig. 2B and C). 


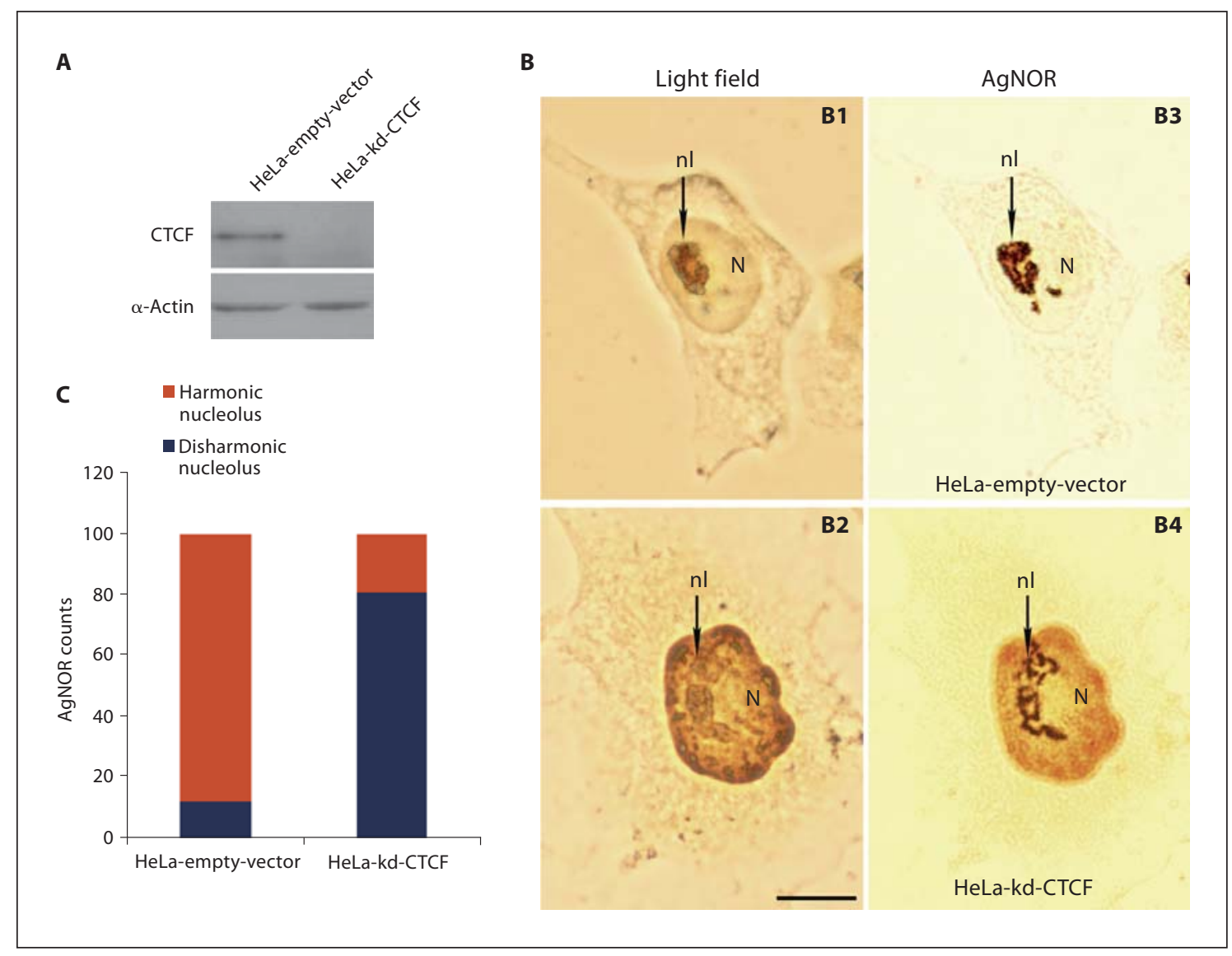

Fig. 1. Evaluation of CTCF depletion effects in HeLa cells. A Western blotting of CTCF from HeLa-kd-CTCF and HeLa-empty-vector protein extracts. B Evaluation of the NORs by the argentic impregnating assay or AgNOR staining. Nucleolus with normal NOR appearance were classified as harmonic (B1, B3), whereas those that displayed a structural disorder at NORs where classified as disharmonic (B2, B4). Arrows point to the stained NORs inside the nucleolus $(\mathrm{nl})$ within the nucleus $(\mathrm{N})$. The bar represents $10 \mu \mathrm{m}$. C Graphic showing percentages of cells with harmonic and disharmonic nucleoli from HeLa-kd-CTCF and HeLa-empty-vector assays, $\mathrm{n}=100$ cells.

Since the DFCs are difficult to identify using conventional staining, we decided to perform ultrastructural AgNOR staining that mainly stains proteins present at such regions in nucleoli from HeLa-empty-vector cells (fig. 2E). AgNOR staining in HeLa-kd-CTCF did not reveal any DFCs inside the nucleolus (fig. 2F), supporting our finding that CTCF absence leads to nucleolar component disorganization.

\section{Effect of CTCF Depletion at the Ultrastructural Level} and in Ribosomal Gene Expression

The presence of CTCF at the DFC has been previously reported [Torrano et al., 2006]. To corroborate the loss of CTCF from the nucleolus under the knockdown condition, we performed ultrastructural immunolocalization.
As expected, CTCF is immunolocalized at the DFCs inside the nucleoli in HeLa-empty-vector cells (fig. 3A) whereas in nucleoli of HeLa-kd-CTCF cells, CTCF is not detectable at the DFCs (fig. 3B). This result confirms the absence of CTCF from the DFCs and indicates a direct role of CTCF in the organization of these nucleolar components. To explore the possibility of a direct effect of CTCF depletion on ribosomal gene transcription we determined the levels of the $28 \mathrm{~S}$ rRNA by qRT-PCR (fig. 3C). Unexpectedly, we observed a 2 -fold increase of the $28 \mathrm{~S}$ rDNA transcript in the absence of CTCF, whereas the levels of fibrillarin and $\beta$-actin were unchanged in HeLa-kdCTCF cells (fig. 3C; see discussion).

Since the AgNOR staining method has been used to evaluate the cellular proliferation state of cancerous cells 

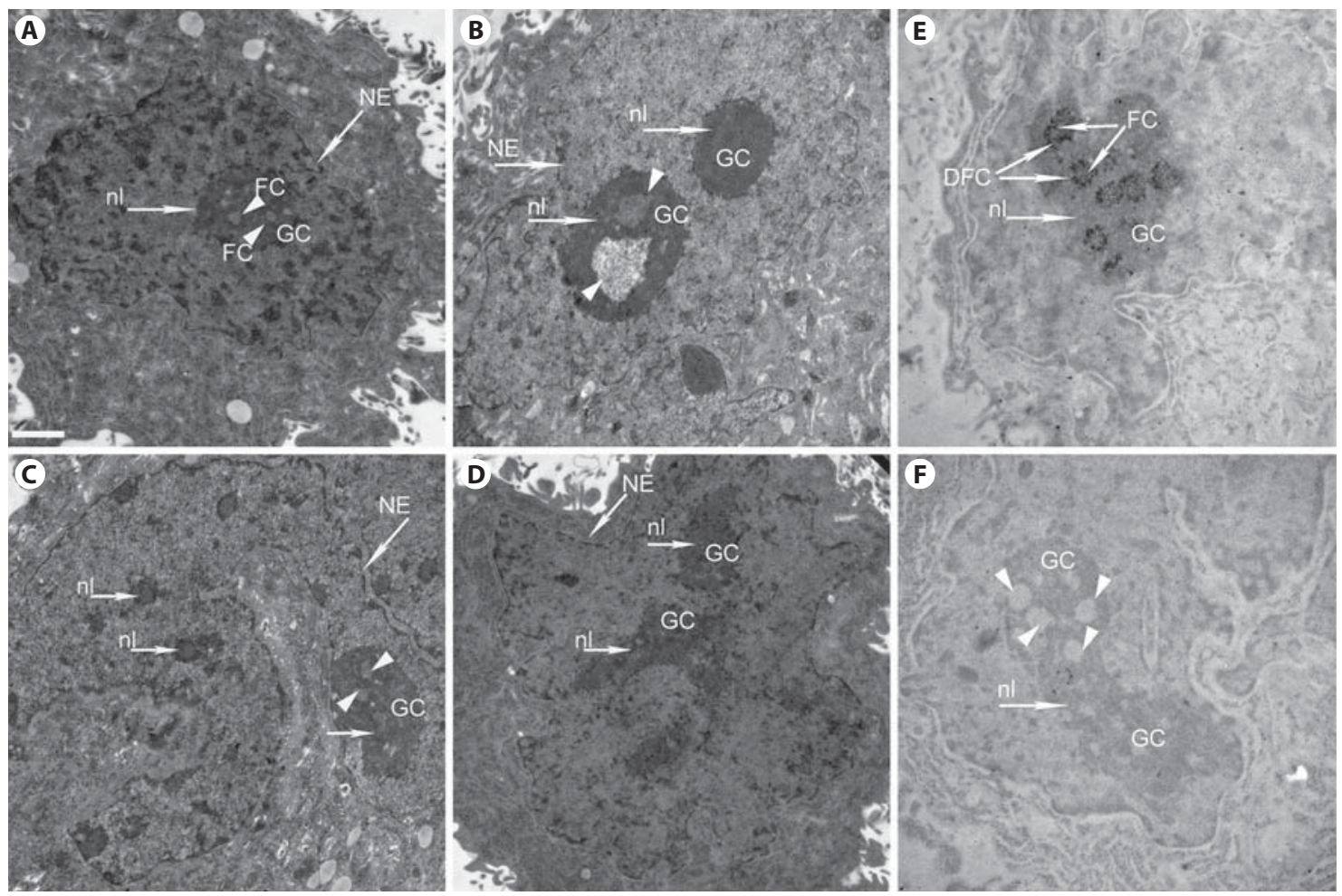

Fig. 2. Ultrastructural analyses of nucleolar components. A Nucleolus (nl) from HeLa-empty-vector cell, granular components (GCs) and fibrillar components (FCs) are indicated. B-D Nucleoli from HeLa-kd-CTCF cells showing several degrees of nucleolus disaggregation and holes (arrowheads) inside the GC. E Ultrastructural AgNOR staining of a nucleolus of a HeLa-empty-vector cell, revealing the intensely stained dense fibrillar components (DFCs) and the less intensely stained FCs inside. The GC surrounds the DFC and is not stained with the AgNOR method. F Ultrastructural AgNOR staining of a nucleolus of a HeLa-kd-CTCF cell with holes (arrowheads) inside the GC and showing no AgNOR staining. NE = Nuclear envelope. The bar represents $1 \mu \mathrm{m}$.

we wondered if the absence of CTCF can also affect HeLa cell proliferation rate [Derenzini et al., 2002]. First of all, in HeLa-kd-CTCF, we did not observe AgNOR positive reactivity in the nucleolus compared to the positive control. However, proliferation rates between HeLa-kdCTCF and HeLa-empty-vector cells were the same (data not shown), indicating that defects in AgNOR staining in HeLa-kd-CTCF cells were not due to a proliferation defect. Together, these results show that CTCF contributes to the nucleolar architecture and regulation of ribosomal gene expression.

\section{Discussion}

In this report we have shown that under CTCF depletion in HeLa cells, nucleolus ultrastructure is altered. We observed a segregation of the GC, and loss of the FCs and
DFCs. These structural defects were accompanied by an upregulation of ribosomal gene transcription. Therefore, we proposed that CTCF might be playing an important role in establishing a proper nucleolus structure and function.

The overall structure of a nucleolus is largely determined by its activity in ribosome biogenesis. For example, cells that have low rates of ribosome biogenesis frequently contain a single small nucleolus, whereas actively growing and cycling mammalian somatic cells, which require a high level of ribosome production, usually have 1 or more large nucleoli. The same relationship can be found in cancer cells, where changes in tumor suppressor and protooncogene expression can upregulate ribosome biogenesis, thus promoting the cell proliferation typical of tumors and 1 or more large nucleoli as in HeLa cells. Any morphological disturbance of the nucleolus is an indicator of an imbalance in the dynamic interaction of the 

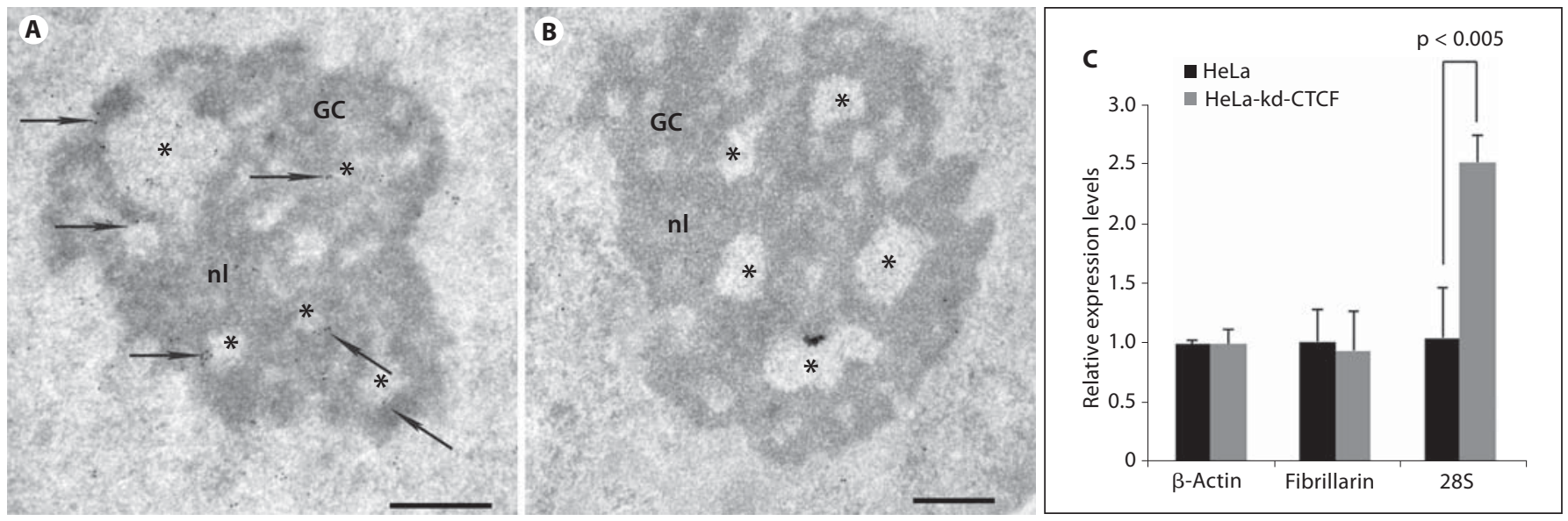

Fig. 3. CTCF distribution at the ultrastructural scale and ribosomal gene expression in HeLa-kd-CTCF cells. A CTCF immunodetection in a nucleolus of a HeLa-empty-vector cell. Gold particles mainly decorate the DFCs (arrows), asterisks depict the FCs. B CTCF immunodetection in a nucleolus of a HeLa-kd-CTCF cell. No labeling was detected on the DFCs, asterisks depict the FCs. The bar represents $500 \mathrm{~nm}$. C qRT-PCR of $28 \mathrm{~S}$ rDNA, fibrillarin and $\alpha$-actin mRNA was performed in HeLa-empty-vector and HeLa-kd-CTCF cells.

nucleolus components [Cisterna and Biggiogera, 2010 and references therein]. In this work we have uncovered CTCF as a structural and physiological regulator of nucleoli components.

We also observed that CTCF localizes to the DFCs inside the nucleolus. As the transcription of the rDNA takes place at the DFCs, our results suggest that CTCF loss from these regions produces an upregulation of ribosomal gene transcription and nucleolus component disorganization. Whether upregulation of ribosomal gene transcription is a direct cause of nucleolus component disorganization or vice versa is an option that we cannot precisely discriminate. However, we favor the hypothesis that the loss of CTCF from the DFCs produces both physiological defects at the same time since CTCF has structural and transcriptional functions.

Historically, it has been described that rRNA genesis is tightly accompanied by transcriptional activation and the concomitant epigenetic silencing of the remaining portion of rDNA repeats [Hernandez-Verdun, 2006]. The presence of CTCF in the DFCs could be mainly determined by the presence of rDNA that needs to be transcriptionally regulated. In mammalian cells $\pm 50 \%$ of rDNA is transcriptionally inactive [McStay and Grummt, 2008]. Furthermore, the methylation-sensitive CTCF binding to the distal promoter of the rDNA [van de Nobelen et al., 2010] and the levels of DNA methylation at such promoters, suggest that indeed CTCF regulates ribosomal gene transcription [Guerrero and Maggert,
2011; and this work]. This initial prediction has recently been confirmed by the demonstration that CTCF binds to a DNA region in proximity to the spacer promoter in vivo [van de Nobelen et al., 2010]. Therefore, it seems reasonable to believe that CTCF binds, in coordination with UBF, to the distal region associated to the spacer promoter in the rDNA repeat. Its role may have to do with the transcription of non-coding intergenic transcripts that regulate the epigenetic state of the chromatin of a subset of rDNA repeats, inhibiting their transcription through heterochromatin formation [Mayer et al., 2006; Santoro et al., 2010]. Then, on the basis of this model, CTCF depletion causes deregulation at the epigenetic level of some repeats derepressing their chromatin structure and causing the upregulation of ribosomal gene expression. At the same time it seems that CTCF organizes the rDNA in the DFCs by interacting with other nucleolus components present in these regions. Thus, loss of CTCF from DFCs impairs rDNA organization, producing the segregated morphology observed in this work.

Heterochromatin formation and maintenance is essential for cell differentiation, nuclear organization and chromosome structure [Peng and Karpen, 2008]. Regarding the nucleolus, heterochromatin is crucial for maintaining its structure and the genomic integrity of rDNA repeats, thus avoiding undesired homologous recombination [McStay and Grummt, 2008]. For example, mutant human cells for the DNA methyl-transferase 1 (DNMT1) showed a severe decrease in rDNA methylation 
concomitant with the binding of the RNA polymerase I, and the abnormal transcription of rDNA copies [Espada et al., 2007]. Moreover, depletion of the nucleolar intergenic non-coding RNA by antisense oligonucleotides caused the dissociation of the NoRC complex from the nucleoli, decreasing DNA methylation and inducing transcriptional activation of rDNA repeats that are normally silenced [Mayer et al., 2006, 2008]. Based upon these data and our current findings, we propose a role of CTCF in heterochromatin formation of the nucleolus by maintaining its structure and through the regulation of the spacer promoter responsible for the non-coding RNA transcription, which is directly linked to heterochromatin formation and rDNA repeat integrity.

On the basis of a recent publication written by Grummt and collaborators, we cannot discard the possibility that CTCF can contribute to the spatial organization of the rDNA repeats [Denissov et al., 2011]. Based on the proposed 'core-helix' model, CTCF provides the 3-dimensional structural foundation for the transcription of ribosomal genes [Denissov et al., 2011]. This alternative function for CTCF can be further supported by its topological role described at many other genomic loci [Hou and Corces, 2011]. Based on our results this seems unlikely, since, instead of losing ribosomal gene expression when CTCF is depleted in HeLa cells, there is a gain of ribosomal gene transcription supporting its role in het- erochromatin formation and silencing of a subset of rDNA repeats.

We conclude that CTCF is a key regulator of nucleolus architecture by organizing the DFCs. Therefore, ribosomal gene transcriptional regulation and nucleolar architecture are 2 mutually dependent processes, to some degree influenced by CTCF, perhaps some of its partners and its own posttranslational modifications, like poly(ADP-ribosyl)ation. How CTCF shapes the nucleolar architecture and regulates rDNA transcription simultaneously needs to be determined in further studies.

\section{Acknowledgements}

We thank Sidney Carter for critical reading of the manuscript and suggestions. This work was supported by the Dirección General de Asuntos del Personal Académico - Universidad Nacional Autónoma de México (IN209403 and IN203811), Consejo Nacional de Ciencia y Tecnología, México (CONACyT; 42653-Q and 128464). E.S.-R., A.H.-H. and C.A.-C. received PhD fellowships from CONACyT and Dirección General de Estudios de Posgrado - Universidad Nacional Autónoma de México (DGEP). Additional support was provided by the $\mathrm{PhD}$ graduate program, 'Doctorado en Ciencias Biomédicas, to the Instituto de Fisiología Celular and the Universidad Nacional Autónoma de México. We are particularly indebted to the excellent technical assistance of Georgina Guerrero Avendaño and members of the F.R.-T. and G.H.V.-N. laboratories.

\section{References}

Barski A, Cuddapah S, Cui K, Roh TY, Schones $\mathrm{DE}$, et al: High-resolution profiling of histone methylations in the human genome. Cell 129:823-837 (2007).

Bierhoff H, Schmitz K, Maass F, Ye J, Grummt I: Noncoding transcripts in sense and antisense orientation regulate the epigenetic state of ribosomal RNA genes. Cold Spring Harb Symp Quant Biol 75:357-364 (2010).

-Caiafa P, Zlatanova J: CCCTC-binding factor meets poly(ADP-ribose) polymerase-1. J Cell Physiol 219:265-270 (2009).

- Cisterna B, Biggiogera M: Ribosome biogenesis: from structure to dynamics. Int Rev Cell Mol Biol 284:67-111 (2010).

-Cuddapah S, Jothi R, Schones DE, Roh TY, Cui $\mathrm{K}$, et al: Global analysis of the insulator binding protein CTCF in chromatin barrier regions reveals demarcation of active and repressive domains. Genome Res 19:24-32 (2009).
De La Rosa-Velázquez IA, Rincón-Arano H, Benítez-Bribiesca L, Recillas-Targa F: Epigenetic regulation of the human retinoblastoma tumor suppressor gene promoter by CTCF. Cancer Res 67:2577-2585 (2007).

Denissov S, Lessard F, Mayer C, Stefanovsky V, van Driel M, et al: A model for the topology of active ribosomal RNA genes. EMBO Rep 12:231-237 (2011)

Derenzini M, Montanaro L, Chilla A, Tosti E, Ceccarelli C, et al: Evaluation of thymidylate synthase protein expression by Western blotting and immunohistochemistry on human 164 colon carcinoma xenografts in nude mice. J Histochem Cytochem 50:1633-1640 (2002).

Espada J, Ballestar E, Santore R, Fraga MF, Villar-Garrea A, et al: Epigenetic disruption of ribosomal RNA genes and nucleolar architecture in DNA methyltransferase 1 (Dnmt1) deficient cells. Nucleic Acids Res 35:21912198 (2007).
Farrar D, Rai S, Chernukhin O, Jagodic M, Ito Y, et al: Mutational analysis of the poly(ADPribosyl)ation sites of the transcription factor CTCF provides an insight into the mechanism of its regulation by poly(ADP-ribosyl) ation. Mol Cell Biol 30:1199-1216 (2010).

-Guelen LP, Brasset E, Meuleman W, Faza MB, Talhout W, et al: Domain organization of human chromosomes revealed by mapping of nuclear lamina interactions. Nature 453: 948-951 (2008).

Guerrero PA, Maggert KA: The CCCTC-Binding Factor (CTCF) of Drosophila contributes to the regulation of the ribosomal DNA and nucleolar stability. PLoS One 6:e16401 (2011).

Hernandez-Verdun D: Nucleolus: from structure to dynamics. Histochem Cell Biol 125: 127-137 (2006).

Hou C, Corces VG: Throwing transcription for a loop: expression of the genome in the $3 \mathrm{D}$ nucleus. Chromosoma (2011). 
-Ishihara K, Oshimura M, Nakao M: CTCF-dependent chromatin insulator is linked to epigenetic remodeling. Mol Cell 23:733-742 (2006).

Kim TH, Abdullaev ZK, Smith AD, Ching KA, Loukinov DI, et al: Analysis of the vertebrate insulator protein CTCF-binding sites in the human genome. Cell 128:1231-1245 (2007).

Martin D, Pantoja C, Fernández Miñan A, Valdes-Quezada C, Moltó E, et al: Genome-wide CTCF distribution in vertebrates defines equivalent sites that aid the identification of disease-associated genes. Nat Struct $\mathrm{Mol}$ Biol18:708-714 (2011).

-Mayer C, Neubert M, Grummt I: The structure of NoRC-associated RNA is crucial for targeting the chromatin remodeling NoRC to the nucleolus. EMBO Rep 9:774-780 (2008).

-Mayer C, Schmitz K-M, Li J, Grummt I, Santoro $\mathrm{R}$ : Intergenic transcripts regulate the epigenetic state of rRNA genes. Mol Cell 22:352361 (2006).

McKeown PC, Shaw PJ: Chromatin: linking structure and function in the nucleolus. Chromosoma 118:11-23 (2009).

McStay B, Grummt I: The epigenetics of rRNA genes: from molecular to chromosome biology. Annu Rev Cell Dev Biol 24:131-157 (2008).
Peng JC, Karpen GH: Epigenetic regulation of heterochromatin DNA stability. Curr Opin Genet Dev 18:204-211 (2008).

Phillips JE, Corces VG: CTCF: master weaver of the genome. Cell 137:1194-1211 (2009).

Recillas-Targa F, De La Rosa-Velazquez IA, SotoReyes E: Insulation of tumor suppressor genes by the nuclear factor CTCF. Biochem Cell Biol 89:479-488 (2011).

Sanij E, Hannan RD: The role of UBF in regulating the structure and dynamics of transcriptionally active rDNA chromatin. Epigenetics 4:374-382 (2009).

-Santoro R, Schmitz K-M, Sandoval J, Grummt I: Intergenic transcripts originating from a subclass of ribosomal DNA repeats silence ribosomal RNA genes in trans. EMBO Rep 11:52-58 (2010)

Schmitz KM, Mayer C, Postepska A, Grummt I: Interaction of noncoding RNA with the rDNA promoter mediates recruitment of DNMT3b and silencing of rRNA genes Genes Dev 24:2264-2269 (2010).

Soto-Reyes E, Recillas-Targa F: Epigenetic regulation of the human p53 gene promoter by the CTCF transcription factor in transformed cell lines. Oncogene 29:2217-2227 (2010)
Torrano V, Navascués J, Docquier F, Zhang R, Burke LJ, et al: Targeting of CTCF to the nucleolus inhibits nucleolar transcription through a poly(ADP-ribosyl)ation-dependent mechanism. J Cell Sci 119:1746-1759 (2006).

Trere D, Ceccarelli C, Montanaro L, Tosti E, Derenzini M: Nucleolar size and activity are related to $\mathrm{pRb}$ and $\mathrm{p} 53$ status in human breast cancer. J Histochem Cytochem 52: 1601-1607 (2004).

van de Nobelen S, Rosa-Garrido M, Leers J, Heath $\mathrm{H}$, Soochit W, et al: CTCF regulates the local epigenetic state of ribosomal DNA repeats. Epigenetics Chromatin 3:19 (2010).

-Yusufzai TM, Tagami H, Nakatani Y, Felsenfeld G: CTCF tethers an insulator to subnuclear sites, suggesting shared insulator mechanisms across species. Mol Cell 13:291-298 (2004).

Zhang R, Burke LJ, Rasko JE, Lobanenkov V, Renkawitz R: Dynamic association of the mammalian insulator protein CTCF with centrosomes and the midbody. Exp Cell Res 294:86-93 (2004).

Zlatanova J, Caiafa P: CTCF and its protein partners: divide and rule? J Cell Sci 122:12751284 (2009). 